\title{
Experimental Investigations of Vegetable Oil Based Cutting Fluids with Extreme Pressure Additive in Machining of AISI 1040 Steel
}

\author{
B. Satheesh Kumar ${ }^{1, ~}$, G. Padmanabhan ${ }^{2}$, P. Vamsi Krishna ${ }^{3}$ \\ ${ }^{1}$ Department of Mechanical Engineering, N.B.K.R. Institute of Science \& Technology, India \\ ${ }^{2}$ Department of Mechanical Engineering, S. V. University College of Engineering, India \\ ${ }^{3}$ Department of Mechanical Engineering, National Institute of Technology, India
}

Copyright (C) 2015 Horizon Research Publishing All rights reserved.

\begin{abstract}
The application of conventional cutting fluids in machining operations is harmful and not eco-friendly. In this context, the present work focuses on environmental friendly cutting fluids such as vegetable oil based cutting fluids (VBCFs). The objective of this work is to determine the influence of vegetable oil based cutting fluids (sesame and coconut oil) with extreme pressure (EP) additive on machining performance. Cutting forces, cutting tool temperature, tool flank wear and surface roughness are measured during turning of AISI 1040 steel with coated carbide tool. Machining performance of VBCFs with EP additive is compared with conventional cutting fluid and VBCFs without EP additive. The results indicated that sesame and coconut oils with EP additive improved machining performance compared to other lubrication conditions. Coconut oil with EP additive decreased the feed force by $31 \%$, thrust force $28 \%$, cutting force $20 \%$, cutting tool temperature $7 \%$ and tool flank wear $34 \%$ and surface quality increased by $33 \%$ compared to sesame oil with EP additive.
\end{abstract}

Keywords Vegetable Oil Based Cutting Fluid, EP Additive, Turning, Cutting Force, Tool Wear, Surface Roughness

\section{Introduction}

Friction is a natural phenomenon that is always encountered in machining. During machining, friction between tool and workpiece lead to rise in high temperatures, which results less dimensional accuracy and poor surface quality of the workpiece. Cutting fluids play the dual role of lubricants and coolants by reducing the friction between tool-workpiece, tool-chip interface. Taylor [1] achieved up to $40 \%$ increase in cutting speed with water as coolant while machining steel using high speed steel (HSS) tool. In another study, efficiency of machining is improved in terms of reduced cutting forces and vibrations, increased tool life, improved surface finish and dimensional accuracy with use of cutting fluids while machining steel with HSS tools $[2,3]$. Chemical composition and mechanical properties of the work material, process performance and finished surface quality influences the selection of tool and cutting fluid. Environmental pollution, dermatitis to operators, soil contamination during disposal and water pollution are the adverse effects due to application of conventional cutting fluids [4-7]. Lubricating additives have good anti-wear properties and often have the disadvantages of being exhaustible over a period, less environmental friendly and inability to repair worn surfaces. Besides these, cost of cutting fluid also incurs a major portion of the total manufacturing cost. These factors have promoted investigations to probe into the use of eco-friendly coolants in machining. Researchers have been started using vegetable oil as cutting fluid alternative to conventional cutting fluids. Cutting fluids based on mineral oils are traditionally used in production shops due to their reusability and chemical stability. However, vegetable oil based cutting fluids (VBCFs) are better substitute for conventional cutting fluids due to their high biodegradability, renewable properties and lower environmental impact to use in machining [8].

From the literature $[9,10]$ it is understood that good physical and chemical adsorption properties, better pitting resistance, lower coefficient of friction, excellent boundary and hydrodynamic lubrication on the metal surface in contact were achieved by VBCFs. Ioan et al. [11] compared the lubricating capacity of rapeseed oil with mineral oil. The results indicated that rapeseed oil has high biodegradability and reduced toxicity for being used in industrial applications. VBCFs have superior performance to conventional cutting fluids, which reduces cutting forces, surface roughness and tool wear, improving surface integrity and tool life. Xavior and Adithan [12] reported the performance of coconut oil and straight cutting fluids during turning of AISI 304 steel 
with carbide tool. Analysis of variance (ANOVA) was made and it was found that feed rate has greater influence on surface roughness ( $62 \%$ contribution) and cutting speed has greater influence on tool wear ( $46 \%$ contribution). The performance of coconut oil based cutting fluid was better than that of mineral oil based cutting fluid. Belluco and De Chiffre [13] evaluated the performance of six cutting oils in drilling AISI 316L austenitic stainless steel using conventional HSS-Co (High Speed Steel-Cobalt) tools. Measurement of tool life, tool wear, cutting forces and chip formation were considered for performance evaluation. VBCFs with different proportion of additive were compared with mineral oil based cutting fluid. The results indicated that VBCFs performed better than the mineral oil based cutting fluid, with $177 \%$ increase in tool life and $7 \%$ reduction in thrust force. Zhang et al. [14] conducted experimental tests to evaluate the effectiveness of a soybean-based cutting fluid applied in CNC turning operations. In this study the effect of soybean-based cutting fluid was compared with petroleum-based cutting fluid when high carbon alloy steel was machined in terms of improving surface finish and reducing tool wear. A statistical analysis of the data indicated that the bio-based cutting fluid performed better compared to petroleum product in terms of improved surface finish and controlling tool wear. Rao et al. [15] conducted a case study using an environmentally friendly soybean-based cutting fluid. This experimental study compared the tool wear in dry cutting, using the soybean based cutting fluid and petroleum based cutting fluid in a $\mathrm{CNC}$ turning operation. It was found that the soybean-based cutting fluid provided a comparable performance as that of the petroleum cutting fluid in controlling tool wear.

Additives of sulfur and organosulfur compounds have been used in commercial cutting fluids, when the sensitivity of the machining operation requires the use of extreme pressure (EP) properties in the fluid. Additive used in cutting fluids is largely confined to sulfur or sulfurized fats. Sulfur additives are well-known for their anti-wear and strong EP characteristics. According to Rastogi and Yadav [16] the sulfur additives have anti-oxidation properties. Cambiella et al. [17] evaluated the performance of oil-in-water emulsions (anionic, non-ionic, and cationic surfactants) in machining operations using EP tests. Results indicated that the performance of emulsions is similar to base oils. The ability of oil droplets plays a key role in their tribological behaviour. Type and concentration of emulsifier affects the performance of lubrication. Bierla et al. [18] carried out physico-chemical analysis in order to evaluate the performance of various sulfur-containing EP additives, and to understand their action mechanism in metal cutting. The purpose of this analysis is to detect the nature of additive reaction products on the surfaces involved in cutting and to correlate them with the milling results in terms of decreased specific cutting energy and tool wear. The results indicated that polysulfide additive exhibited the best efficiency in terms of decreased specific cutting energy and tool wear. Ozcelik et al. [19] compared the performance of EP additive included in canola oil and sunflower oil during turning of AISI 304L austenitic steel. The performance of VBCFs with $8 \%$ and $12 \%$ sulfur based EP additive were evaluated in terms of cutting and feed forces, tool wear and surface roughness. Obtained results were also compared with dry cutting conditions. Results indicated that $8 \%$ of EP additive contributed canola oil based cutting fluid gave better performance than that of semi-synthetic and mineral oil based cutting fluids in terms of reduced surface roughness, feed force and tool wear. Also, the results indicated that the surface quality improved by $35 \%$. Feed forces were reduced in the range of $5.51-26.31 \%$. Kuram et al. [20] employed D-optimal experimental design method in machining for performance analyses of six cutting fluids. Effects of experimental parameters such as spindle speed, feed rate and depth of cut were studied with four different VBCFs formulated from sunflower and canola oils (including $8 \%$ and $12 \%$ of EP additives) and two commercial cutting fluids in the turning process. Parameters of performance criteria were surface roughness $\left(\mathrm{R}_{\mathrm{a}}\right)$, cutting force $\left(\mathrm{F}_{\mathrm{z}}\right)$ and feed force $\left(\mathrm{F}_{\mathrm{x}}\right)$ during turning of AISI $304 \mathrm{~L}$ with carbide tool. The analyses of variance were applied to determine the effect of all cutting fluids on surface roughness, cutting and feed forces. Results indicated that sunflower-based CF with $8 \%$ of EP and commercial semi-synthetic cutting fluid performed better than the rest of cutting fluids for reducing surface roughness and forces. Kuram et al. [21] investigated the effect of EP additive included VBCFs in terms of reduced cutting force, increased tool life and improved surface finish during end milling of AISI 304 stainless steel. The experiments were conducted with three different VBCFs developed from sunflower with $8 \%$ EP, canola oil with $8 \%$ EP and a commercial type of semi-synthetic cutting fluid. Cutting fluid was applied to the cutting zone via two nozzles. Results indicated that canola oil with $8 \%$ EP additive showed better performance than others.

In the present work, VBCFs are prepared with $5 \%$ of EP additive addition to sesame and coconut oil. As a preliminary experimentation, to test the performance of sesame and coconut oil with sulfur based EP additive (HiTEC343) only $5 \%$ is added. Based on the literature review and the basic properties of selected vegetable oils and EP additive, the percentage of the EP additive is selected to test the applicability of prepared VBCFs in machining. Experiments are conducted in different lubrication conditions including conventional cutting fluid, vegetable oils without EP additive and vegetable oils with EP additive. Machining performance is measured in terms of feed force $\left(F_{x}\right)$, thrust force $\left(\mathrm{F}_{\mathrm{y}}\right)$ and cutting force $\left(\mathrm{F}_{\mathrm{z}}\right)$, cutting tool temperature, tool flank wear and surface roughness $\left(\mathrm{R}_{\mathrm{a}}\right)$ during turning of AISI 1040 steel with coated carbide tool.

\section{Experimental Details}

All the machining experiments are conducted on PSG-124 
lathe with coated carbide tool (CNMG120408S4P30) and heat treated AISI 1040 steel of $30 \pm 2$ HRc (Rockwell Hardness) as workpiece. Machining is conducted by application of conventional cutting fluid prepared by soluble oil (SO), sesame oil based cutting fluid with $0 \%$ of EP additive (SCF0), sesame oil based cutting fluid with $5 \%$ of EP additive (SCF5), coconut oil based cutting fluid with $0 \%$ of EP additive (CCF0) and coconut oil based cutting fluid with $5 \%$ of EP additive (CCF5). Sulfur based EP additive (HiTEC343) is used to prepare VBCFs. Sulfur based EP additive is added to VBCFs because the sulfur additive possesses low viscosity values, good solubility in water and high lubricating functions [22].

For preparing cutting fluid, initially emulsifier and vegetable oil are mixed in the ratio of $15 \%$ and $85 \%$ by weight respectively. Then, EP additive is added to the mixture. EP additive is added to the mixture by varying the proportion of vegetable oil. Vegetable oil based cutting fluid is mixed with water in oil to water ratio of 9:100. In the present work, EP additive in vegetable oil is varied as $0 \%$ and $5 \%$ by weight. The experimental setup is developed for liquid lubricant supply of $3.5 \mathrm{l} / \mathrm{min}$ at the machining zone.

Initially experiments are conducted at constant cutting conditions (cutting speed, V: $80 \mathrm{~m} / \mathrm{min}$; feed rate, f: 0.14 $\mathrm{mm} / \mathrm{rev}$; depth of cut: $0.5 \mathrm{~mm}$ ) and then with varying cutting speeds $(60,80$ and $100 \mathrm{~m} / \mathrm{min})$, feed rates $(0.14,0.17$ and $0.20 \mathrm{~mm} / \mathrm{rev})$ and constant depth of cut (d.o.c. $=0.5 \mathrm{~mm})$ to observe the effect. Feed force $\left(F_{x}\right)$, thrust force $\left(F_{y}\right)$ and cutting forces $\left(\mathrm{F}_{\mathrm{z}}\right)$ are recorded using KISTLER 9272 dynamometer. Cutting tool temperature during turning is measured by thermocouple (K-type shielded) embedded at the bottom of the tool insert in the tool holder. The experimental setup is shown in Fig. 1. An optical projector (OLYMPUS GX51) with magnification (5x to 100x) is employed to measure tool flank wear. Surface roughness tester (Surf test, SJ-301, MITUTOYO, stylus material: diamond; tip radius: $5 \mu \mathrm{m}$ ) is employed for measuring average surface roughness $\left(R_{a}\right)$ of machined surface.

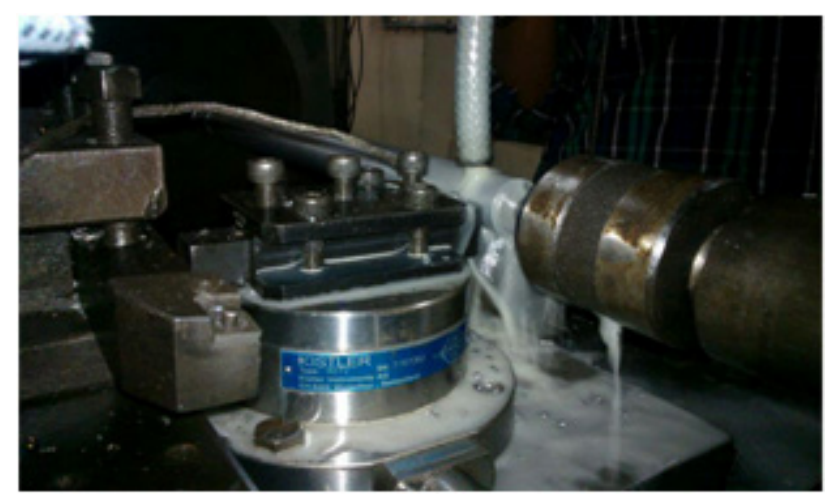

Figure 1. Detail of experimental setup

\section{Results and Discussions}

Machining performance of VBCFs with EP additive is evaluated by measuring feed, thrust and cutting forces, cutting tool temperature, tool flank wear and surface roughness in turning operation and compared with conventional cutting fluid and VBCFs without EP additive.

\subsection{Machining Performance at Constant Cutting Conditions}

The performance of machining at different lubricating conditions such as conventional cutting fluid, SCF0, SCF5, $\mathrm{CCF} 0$ and $\mathrm{CCF} 5$ are evaluated at constant cutting conditions.

\subsubsection{Cutting forces}

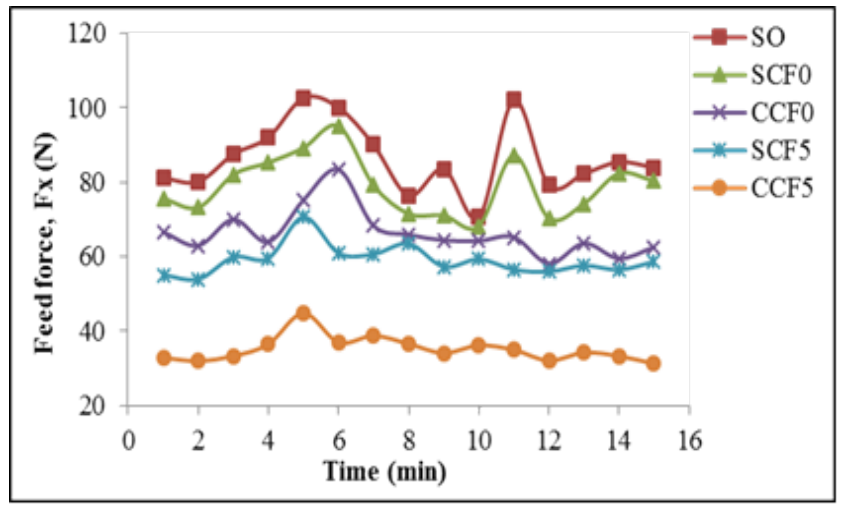

Figure 2. Variation of feed force $\left(\mathrm{F}_{\mathrm{x}}\right)$ with respect to time for different cutting fluids

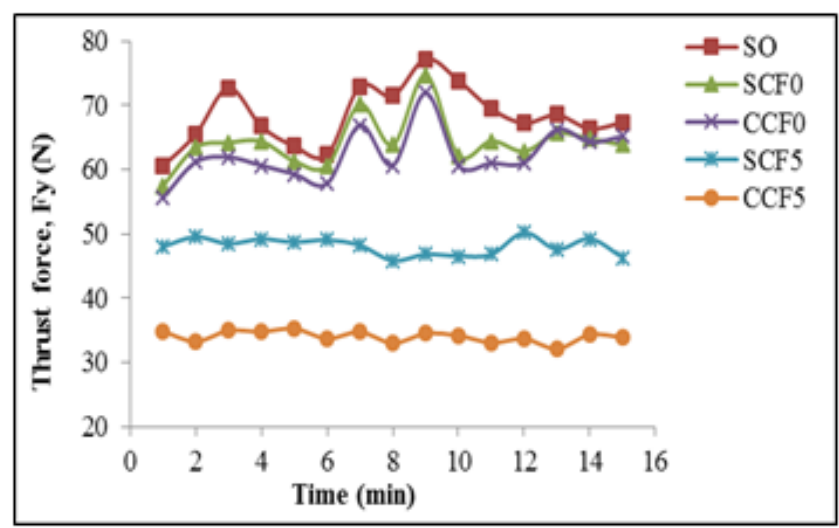

Figure 3. Variation of thrust force $\left(\mathrm{F}_{\mathrm{y}}\right)$ with respect to time for different cutting fluids

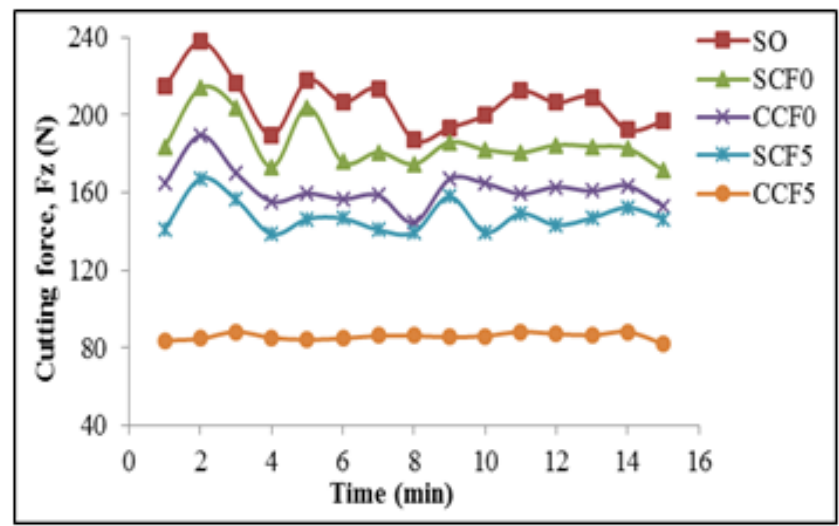

Figure 4. Variation of cutting force $\left(\mathrm{F}_{\mathrm{z}}\right)$ with respect to time for different cutting fluids 
Feed force $\left(F_{x}\right)$ with respect to time for different lubricating conditions during machining of AISI 1040 is presented in Fig. 2. Thrust force $\left(\mathrm{F}_{\mathrm{y}}\right)$ with respect to time for different lubricating conditions is shown in Fig. 3. Cutting force $\left(\mathrm{F}_{\mathrm{z}}\right)$ with respect to time is presented in Fig. 4 . The forces are reduced with addition of EP additive in vegetable oil compared to conventional cutting fluid and base oils. Same trend is observed in all three components of forces. The lubricant effectiveness in minimizing the frictional affects at the tool and workpiece interaction in case of EP additive assisted machining is evident from the reduced cutting forces compared to other lubricating cutting conditions. Even though more variation is not noted, CCF5 has shown better performance compared to other lubricating conditions. The order of the cutting fluids performances from the highest to lowest level is followed as CCF5, SCF5, CCF0, SCF0 and conventional cutting fluid. Values of SCF5 and CCF5 are found to be very close to each other. CCF5 showed better performance than SCF5. This trend may be attributed to the better lubricating properties of coconut oil and basic nature of EP additive [12]. As the EP additive reacts with the surface and forms lead sulfide and iron chloride with low shear strength at the workpiece, with this plastic deformation eases up and leads to reduction in feed, thrust and cutting forces [23].

\subsubsection{Cutting Tool Temperature}

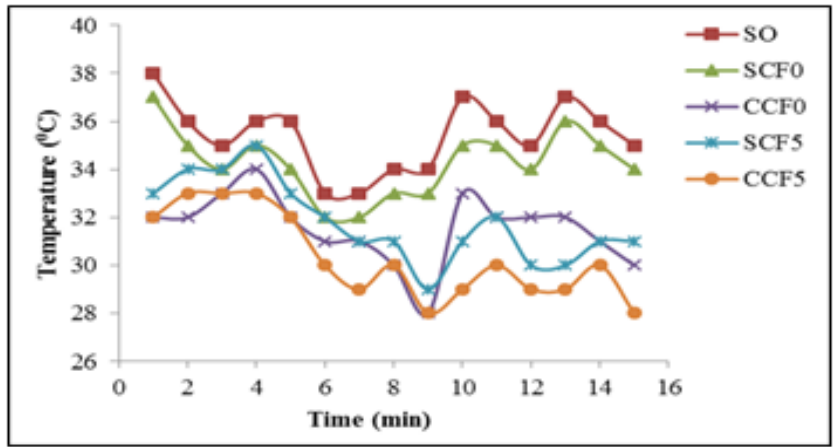

Figure 5. Variation of cutting tool temperature with respect to time for different cutting fluids

Cutting tool temperature during the turning operation is measured at nodal point and presented in Fig. 5. The cutting tool temperature is low and almost same at all other lubricating conditions. Much difference is not observed among VBCFs. Performances of the VBCFs can be listed in the decreasing order for the cutting tool temperature as CCF5, SCF5, CCF0, SCF0 and SO. Temperature is less in case of EP additive assisted machining. This is because of the combined effect of EP additive and vegetable oil. The result is implied by the low coefficient of friction as EP additive soften at elevated temperatures. Thermal conductivity of EP additive mixture enables to decrease in tool temperature. In terms of EP additive, $5 \%$ of EP included coconut oil based cutting fluid showed better performance than $5 \%$ of EP included sesame oil based cutting fluid. Lubricating the cutting tool reduces the coefficient of friction between chip and tool. Lubricating film provided by vegetable oils, being intrinsically strong and lubricious, improves workpiece quality and overall process productivity by reducing friction and heat generation. The cutting fluid prevents intimate contact between the surface of chip and tool face. In spite of the lubricating and cooling action of cutting fluids there always exists some metal to metal contact between the tool and chip, temperature generated is high enough to weld the contacting asperities of the metal. This is prevented by adding EP additive to the VBCFs. EP additive generates a soapy film which prevents particles of metal from welding, which reduces the cutting tool temperature [13].

\subsubsection{Tool Flank Wear}

Performance of VBCFs in reducing tool flank wear is represented in Fig. 6. Tool flank wear increases with machining time generally in any machining operation. After 15 minutes of machining time the observed tool wear is less in SCF5 and CCF5 compared to other lubricating cutting fluids. Tool flank wear is reduced with application of VBCFs compared to soluble oil, however the reduction in tool flank wear is more significant with EP additive. The rate of flank wear is less in EP additive assisted machining compared to conventional cutting fluid and cutting fluid without EP additive machining. During cutting process heat is generated at the primary deformation zone and secondary deformation zone, and induces high cutting temperatures. Under such high cutting temperatures, the EP additive mixture creating a thin lubricating film on the workpiece and causes to reduction of flank wear. Among CCF5 and SCF5, CCF5 showed better performance. Using VBCFs with EP additive, the tool flank wear decreased compared to VBCFs without EP additive. Reduction of tool flank wear could be attributed to the fatty acid content in VBCFs results in significant reduction in friction and wear. Cooling and lubricating effect of EP additive also added to vegetable oil.

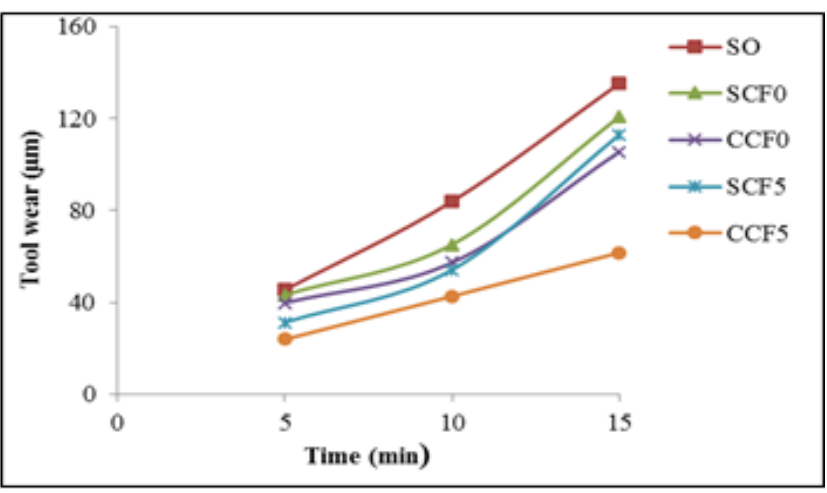

Figure 6. Variation of tool flank wear with respect to time for different cutting fluids

\subsubsection{Surface Roughness}

To specify performances of cutting fluids, average value of the surface roughness for each cutting fluid is analyzed and is represented in Fig. 7. The average value of surface roughness is measured after 15 minutes of machining time. Among the VBCFs the surface roughness is less with application of CCF5. This indicates better lubrication 
characteristics of CCF5. In terms of EP additive, $5 \%$ of EP included CCF showed better performance (value of the least surface roughness) than 5\% of EP additive included SCF. This may be because of high lubrication property of VBCFs, which reduced the frictional forces and temperature between the tool and workpiece, thus prolonging tool life, resulting in the lower surface roughness values [19]. EP additives contain molecular compounds that react with metal surfaces under extreme friction conditions, producing a protective film that prevents welding and surface damage. The additives activates when pressure and temperature rise during the machining process. When properly applied, the compounds in EP additives enhance the ability of metalworking fluids to provide improved surface finish. Decreasing shear stresses on the surface increases built up edge (BUE) with addition of EP additive [24]. Consequently, addition of EP additive in cutting fluids showed the lower surface roughness value. As is the case with cutting forces and tool wear, the results indicated better towards addition of EP additive in vegetable oil. This is because of the lubricating action of the EP additive and vegetable oil. This could be due to the reduction in the cutting forces.

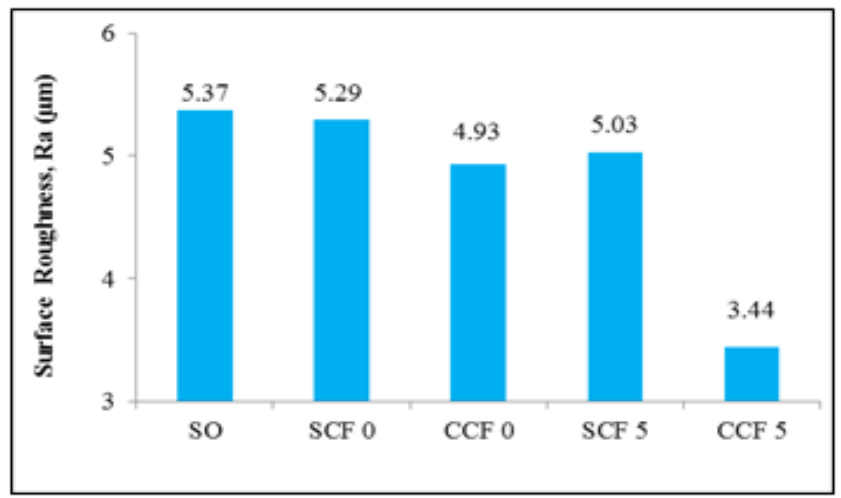

Figure 7. Variation of surface roughness $\left(\mathrm{R}_{\mathrm{a}}\right)$ for different cutting fluids

\subsection{Machining Performance at Varying Cutting Conditions}

The performance of machining with SCF5 and CCF5 under varying cutting conditions is evaluated through parameters like feed, thrust and cutting forces, cutting tool temperature, tool flank wear and surface roughness.

\subsubsection{Cutting forces}

Performances of $5 \%$ of EP additive included in VBCFs on feed force $\left(\mathrm{F}_{\mathrm{x}}\right)$ with respect to cutting speed during machining of AISI 1040 steel is measured and shown in Fig. 8. Feed force increased with increase in cutting speed and decreased with further increase in cutting speed. Thrust force $\left(\mathrm{F}_{\mathrm{y}}\right)$ with respect to cutting speed for different lubricating conditions during turning operation is presented in Fig. 9. Thrust force increased with increase in cutting speed and decreased with further increase in cutting speed. Cutting force $\left(\mathrm{F}_{\mathrm{z}}\right)$ with respect to cutting speed during turning operation is presented in Fig. 10 for different lubricating conditions. Cutting force increased with increase in cutting speed and decreased with further increase in cutting speed.
Feed, thrust and cutting forces are first increased slightly and then decreased with further increase in cutting speed. The cause for drop in cutting force is attributed to the reduction in the yield strength of the workpiece material due to increase in the shear zone temperature. Shear localization takes place in primary and secondary shear deformation zones. It leads to lowered dynamic cutting forces with a sudden drop in the static cutting force, due to thermal softening in the secondary shear deformation zone. These factors attribute to the reduction of cutting forces. Also, performances of $5 \%$ of EP additive included in VBCFs on feed force $\left(\mathrm{F}_{\mathrm{x}}\right)$ with respect to feed rate during machining of AISI 1040 steel is presented in Fig. 11. Feed force increased with increase in feed rate. Thrust force $\left(\mathrm{F}_{\mathrm{y}}\right)$ with respect to feed rate during machining for different lubricating conditions is presented in Fig. 12. Thrust force increased with increase in feed rate. Cutting force $\left(\mathrm{F}_{\mathrm{z}}\right)$ with respect to feed rate during machining is evaluated and results are shown in Fig. 13 for different lubricating conditions. Cutting forces are increased with increase in feed rate. The reason behind this is, larger amount of material removal due to increased feed rate creates more material deformation which in turn requires more force. The order of the cutting fluid performances from the highest level to the lowest level is followed as CCF5 and SCF5. Cutting forces are slightly reduced with EP additive in CCF5 compared to SCF5. Same trend is observed in all three components of cutting forces. This could be attributed to better lubrication property of $\mathrm{VBCFs}$, which reduced the frictional forces between the tool and workpiece.

CCF5 has shown better result compared to SCF5. CCF5 decreased the feed force by $31 \%$, thrust force $28 \%$, cutting force $20 \%$ compared to SCF5. With addition of EP additive in VBCFs boundary lubrication conditions are achieved, as EP additive react chemically with the metal to form compounds on the metal surface. These compounds form layered surfaces which are easily sheared in sliding thus reducing friction; or these inhibit the welding which would occur with bare metal surface in contact, which results reduction in cutting forces. This phenomenon seems to be more effective with coconut oil because of its high percentage of saturated fatty acid content compared to sesame oil. In addition, low viscosity property of coconut oil decreased the frictional forces thereby reduced the cutting forces compared to sesame oil.

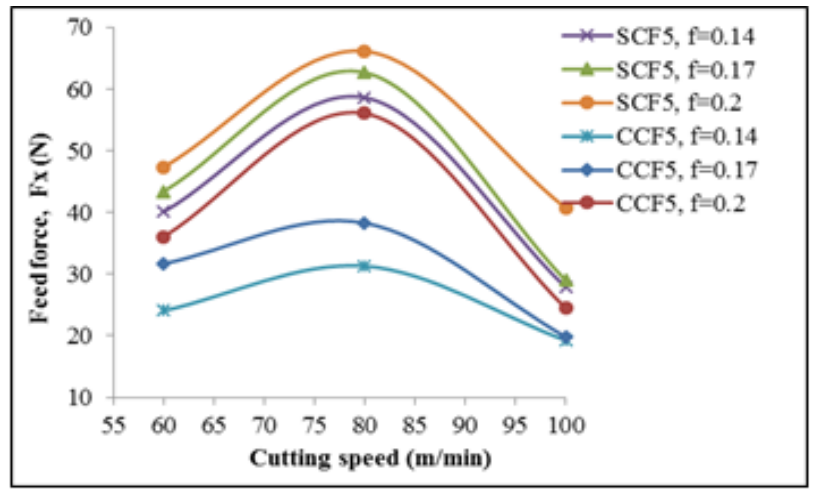

Figure 8. Variation of feed force $\left(\mathrm{F}_{\mathrm{x}}\right)$ with respect to cutting speed for different cutting fluids (d.o.c. $=0.5 \mathrm{~mm}$, time $=15 \mathrm{~min}$ ) 


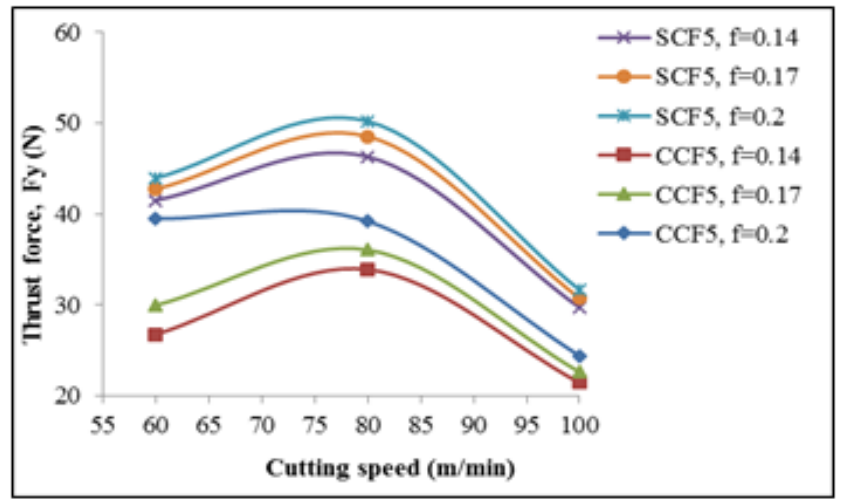

Figure 9. Variation of thrust force $\left(F_{y}\right)$ with respect to cutting speed for different cutting fluids (d.o.c. $=0.5 \mathrm{~mm}$, time $=15 \mathrm{~min}$ )

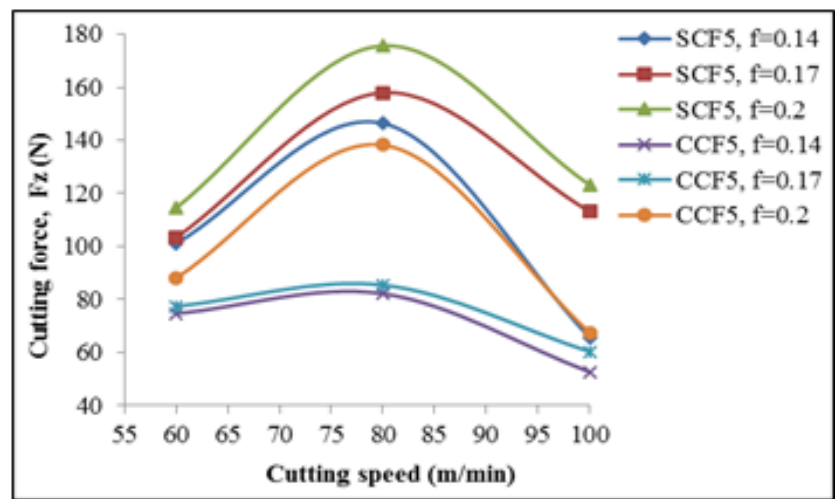

Figure 10. Variation of cutting force $\left(\mathrm{F}_{\mathrm{z}}\right)$ with respect to cutting speed for different cutting fluids (d.o.c. $=0.5 \mathrm{~mm}$, time $=15 \mathrm{~min}$ )

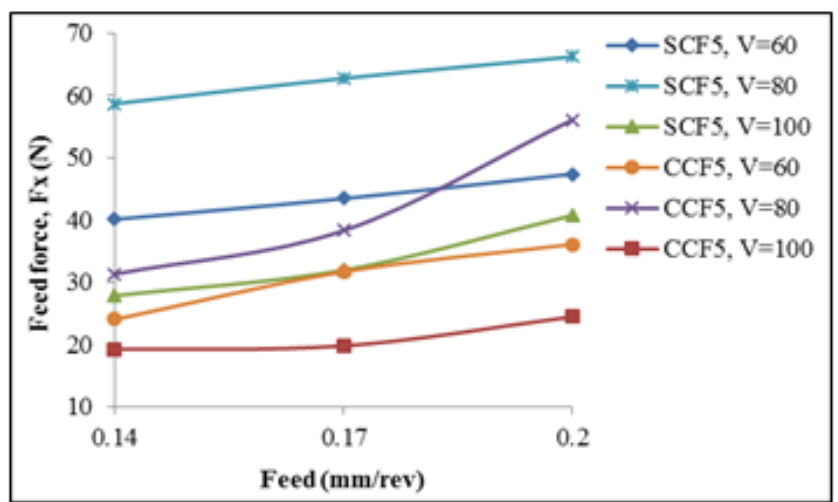

Figure 11. Variation of feed force $\left(\mathrm{F}_{\mathrm{x}}\right)$ with respect to feed for different cutting fluids (d.o.c. $=0.5 \mathrm{~mm}$, time $=15 \mathrm{~min}$ )

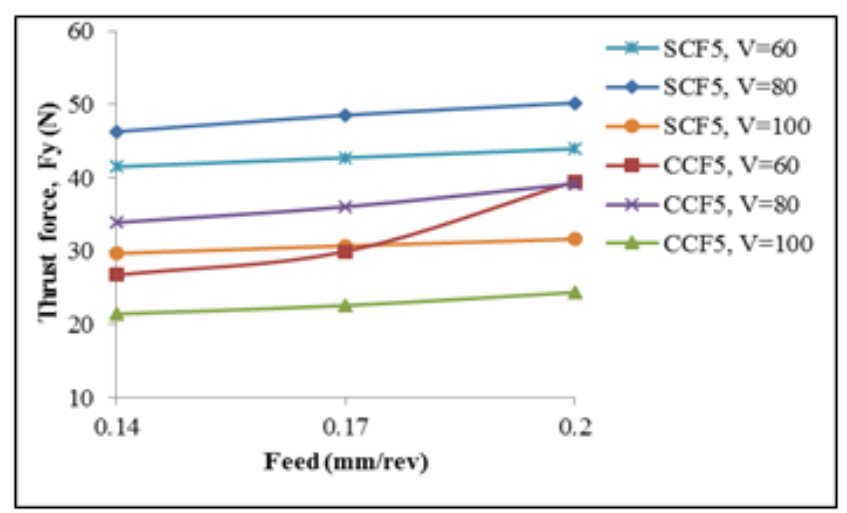

Figure 12. Variation of thrust force $\left(\mathrm{F}_{\mathrm{y}}\right)$ with respect to feed for different cutting fluids (d.o.c. $=0.5 \mathrm{~mm}$, time $=15 \mathrm{~min}$ )

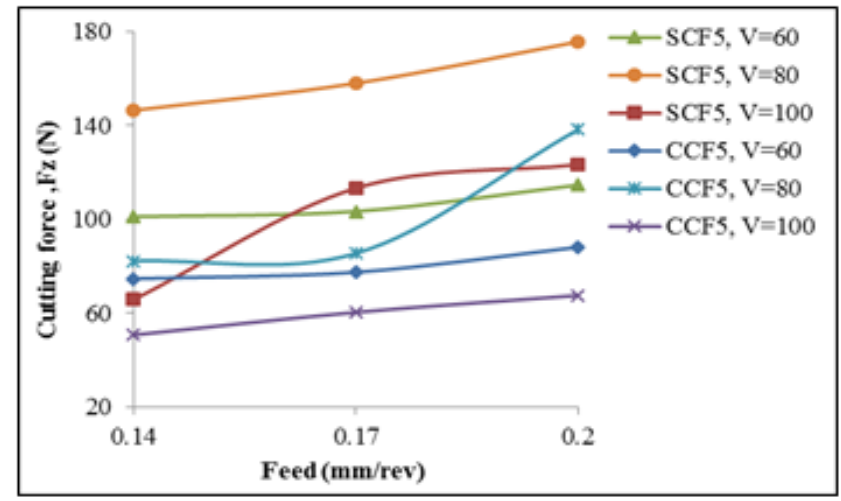

Figure 13. Variation of cutting force $\left(\mathrm{F}_{\mathrm{z}}\right)$ with respect to feed for different cutting fluids (d.o.c. $=0.5 \mathrm{~mm}$, time $=15 \mathrm{~min}$ )

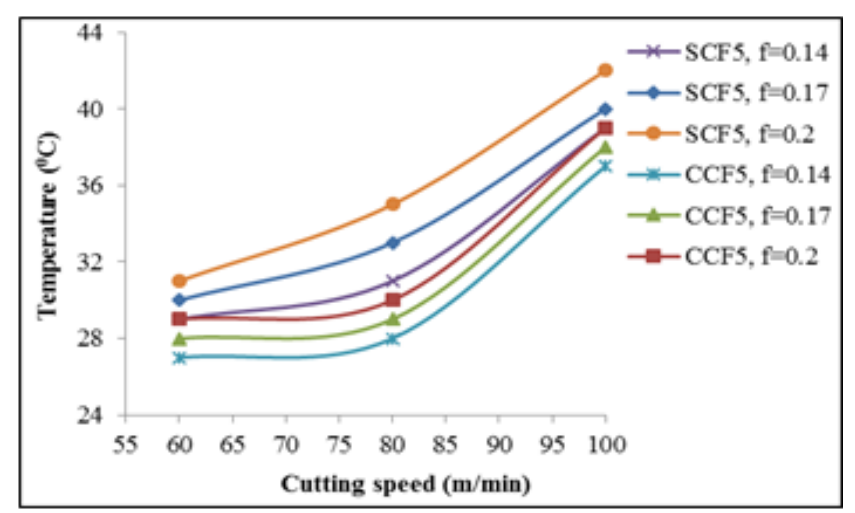

Figure 14. Variation of cutting tool temperature with respect to cutting speed for different cutting fluids (d.o.c. $=0.5 \mathrm{~mm}$, time $=15 \mathrm{~min}$ )

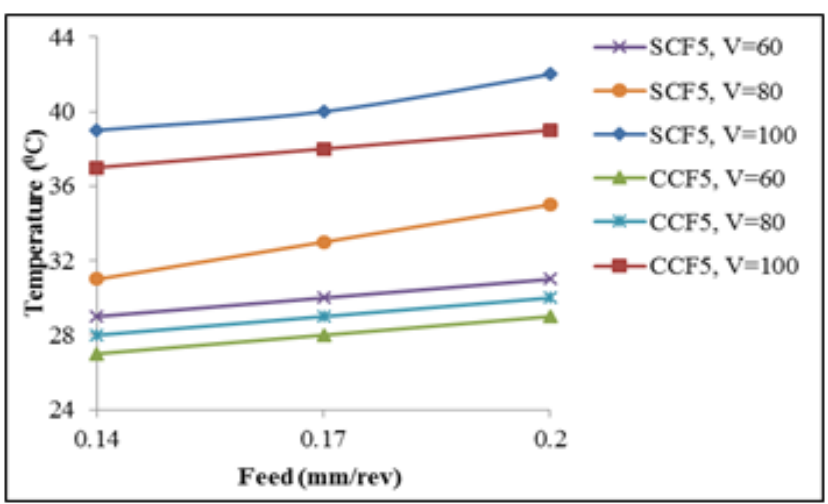

Figure 15. Variation of cutting tool temperature with respect to feed for different cutting fluids (d.o.c. $=0.5 \mathrm{~mm}$, time $=15 \mathrm{~min}$ )

\subsubsection{Cutting Tool Temperature}

Cutting tool temperature with respect to cutting speed during turning operation is measured at nodal point and presented in Fig. 14. Nodal temperature increases with increase in cutting speed. Variation of cutting tool temperature with respect to feed is presented in Fig. 15. Cutting tool temperature increased with increase in feed rate. This is due to higher metal removal rates causing more plastic deformation in the primary shear zone. As the major portion of the heat is transferred to the chip and only a small portion is conducted to the work material, causing a lower temperature rise of the workpiece. CCF5 consistently showed better performance compared to SCF5. CCF5 
decreased cutting tool temperature by $7 \%$ compared to SCF5. As discussed in section 3.1.2, lubricating film formed by vegetable oils, prevention of weld between contacting asperities by EP additive results in lower cutting tool temperatures. Among sesame oil and coconut oil, this tendency is more significant in coconut oil, because of the soapy film formation of EP additive in coconut oil, which leads to reduction in coefficient of friction. This is because of the combined effect of EP additive and coconut oil. The result is implied by the low coefficient of friction as EP additive soften at elevated temperatures. Also the thermal conductivity of EP additive mixture enables to decrease in tool temperature.

\subsubsection{Tool Flank Wear}

Performance of VBCFs including 5\% EP additive in reducing tool flank wear with respect to cutting speed is shown in Fig. 16. Tool flank wear measured at different lubricating conditions with respect to feed is represented in Fig. 17. With increase in cutting speed and feed rate tool wear increases generally in any machining operation. Same trend is observed in VBCF with EP additive. Tool wear is very less in CCF5 compared to SCF5. CCF5 decreased the tool flank wear by $34 \%$ compared to SCF5. Under high cutting temperatures, EP additive creates a thin lubricating film on the workpiece and tool. The EP additive with vegetable oil flow at the interface and decrease the plastic contacts, leading to reduction in tool flank wear. Low coefficient of friction, sliding action and low shear resistance within the contact interface reduce flank wear [18]. Reduction of tool flank wear could be attributed to the fatty acid content in VBCFs results in significant reduction in friction and wear. Cooling and lubricating effect of EP additive also added to vegetable oil. The combined effect of EP additive and vegetable oil caused to reduction in tool flank wear, which is more effective with 5\% EP additive in coconut oil.

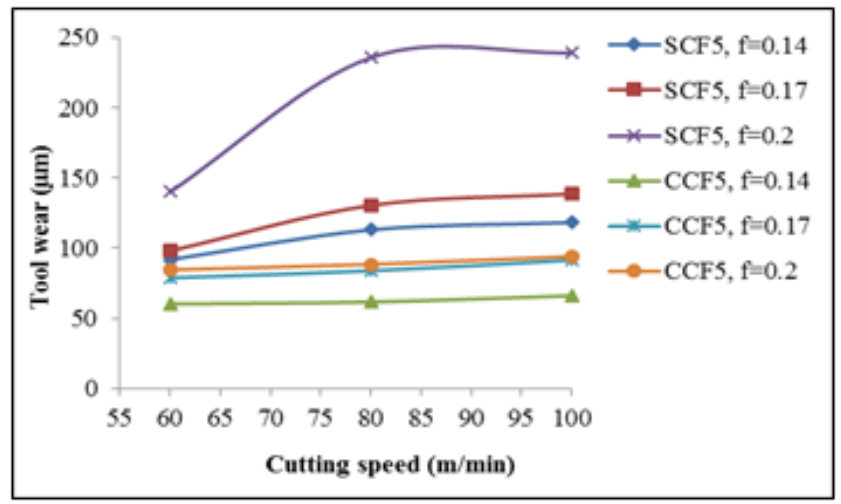

Figure 16. Variation of tool flank wear with respect to cutting speed for different cutting fluids (d.o.c. $=0.5 \mathrm{~mm}$, time $=15 \mathrm{~min}$ )

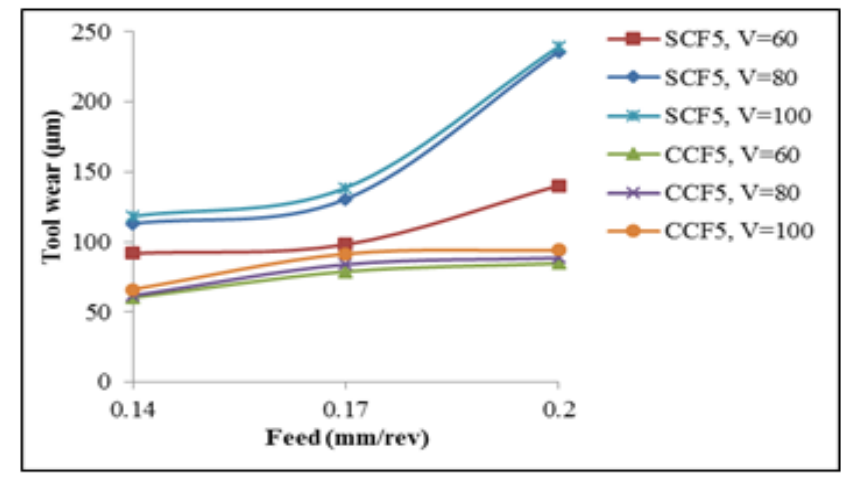

Figure 17. Variation of tool flank wear with respect to feed for different cutting fluids (d.o.c. $=0.5 \mathrm{~mm}$, time $=15 \mathrm{~min}$ )

\subsubsection{Surface Roughness}

Performance of SCF and CCF including 5\% EP additive in reducing surface roughness with respect to cutting speed and feed is represented in Fig. 18 and 19 respectively. Surface roughness is less with application of $5 \%$ of EP including $\mathrm{CCF}$, which indicates better lubrication characteristics of CCF5. With the application of CCF5 the surface quality improved by $33 \%$ compared to SCF5. Sulfur based EP additives provides stable film of lubrication at the tool chip interface. With addition of EP additive in cutting fluids, decreasing shear stresses on the surface and increased built up edge (BUE) formation. Consequently, with addition of EP additive in VBCFs showed the lower surface roughness values [24]. Like in cutting forces, cutting tool temperatures and tool wear, the combined effect of EP additive and coconut oil is better compared to other lubricating conditions. The reduction in surface roughness in case of EP additive in coconut oil may be attributed to its better lubricating action, which reduced the frictional forces between the tool and workpiece thereby reducing the temperatures developed and ultimately preventing tool wear, thus prolonging tool life, resulting in improved surface quality.

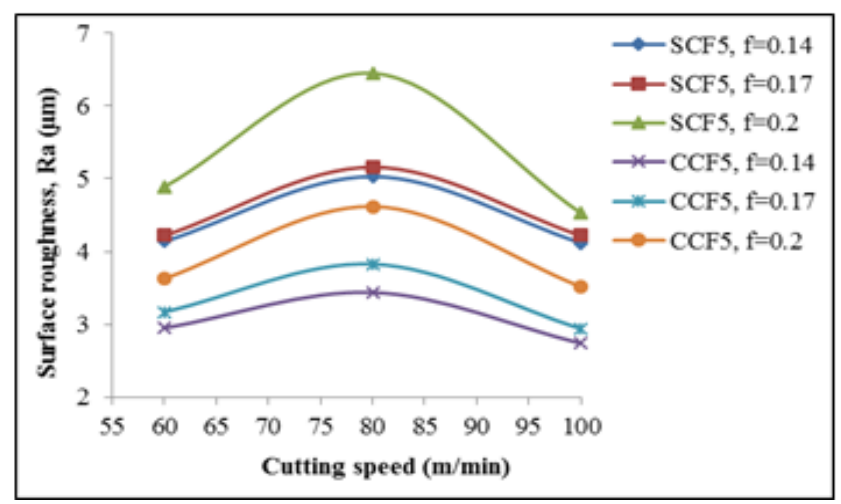

Figure 18. Variation of surface roughness (Ra) with respect to cutting speed for different cutting fluids (d.o.c. $=0.5 \mathrm{~mm}$, time $=15 \mathrm{~min}$ ) 


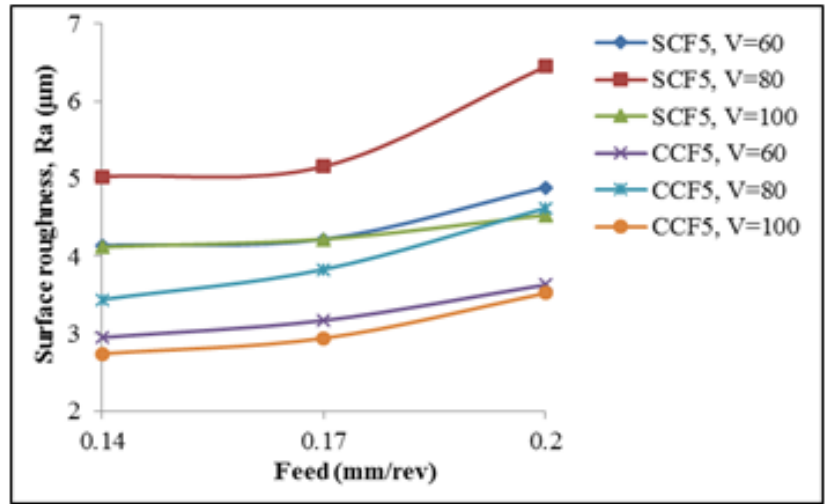

Figure 19. Variation of surface roughness (Ra) with respect to feed for different cutting fluids (d.o.c. $=0.5 \mathrm{~mm}$, time $=15 \mathrm{~min}$ )

\section{Conclusions}

Performances of VBCFs are evaluated in the present work with and without addition of EP additive. Coconut oil and sesame oil with and without EP additive are employed in machining at constant cutting conditions and performance is evaluated by comparing with conventional cutting fluid machining. Further, the performance of SCF and CCF with EP additive are evaluated with varying cutting speed and feed rate.

- At constant cutting conditions, SCF and CCF with EP additive improved machining performance by reducing feed, thrust and cutting forces, cutting tool temperature, tool flank wear and surface roughness.

- At varying cutting conditions SCF and CCF with EP additive, feed, thrust and cutting forces and surface roughness reduced, whereas cutting tool temperature and tool flank wear increased with increase in cutting speed.

- At varying cutting conditions SCF and CCF with EP additive, feed, thrust and cutting forces, cutting tool temperature, tool flank wear and surface roughness was increased with increase in feed rate.

- Among sesame and coconut oils with and without EP additive, the improvement in performance is significant with CCF5. CCF5 decreased the feed force by $31 \%$, thrust force $28 \%$, cutting force $20 \%$, cutting tool temperature $7 \%$ and tool flank wear $34 \%$ and surface quality increased by $33 \%$ compared to SCF5.

\section{REFERENCES}

[1] Taylor, F.W., 1907. On the art of cutting metals. Transactions ASME 28, 31-58.

[2] De Chiffre, L., 1988. Function of cutting fluids in machining. Journal of Lubrication Engineering 44, 514-518.

[3] De Chiffre, L., Lassen, S., Pedersen, K.B., Skade, S., 1994. A reaming test for cutting fluid evaluation. Journal of Synthetic
Lubrication 11, 17-34.

[4] Bennett, E.O., 1983. Water based cutting fluids and human health. Tribology International 16, 133-136.

[5] Shashidhara, Y.M., Jayaram, S.R., 2010. Vegetable as a potential cutting fluid - An evaluation. Tribology International 43, 1073-1081.

[6] Howes, T. D., Toenshoff, H. K., Heuer, W., 1991. Environmental aspects of grinding fluids. Annals of CIRP, 40(2), 623-629.

[7] Byrne, G., Scholta, E., 1993. Environmentally clean machining processes- A strategic approach. Annals of CIRP, 42(1), 471- 474 .

[8] Mathew, T.S., Nader, S., Bigyan, A., Lambert, A.D., 2007. Influence of fatty acid composition on the tribological performance of two vegetable-based lubricants. Journal of Synthetic Lubrication 24, 101-110.

[9] Adhvaryu, A., 2004. Tribological studies of thermally and chemically modified vegetable oils for use as environmentally friendly lubricants. Wear 257, 359-367.

[10] Fox, N.J., Stachowiak, G.W., 2007. Vegetable oil based lubricants - A review of oxidation. Tribology International 40, 1035-1046.

[11] Ioan, I.S., Camelia, C., George, C., 2002. On the future of biodegradable vegetable lubricants used for industrial trybosystems. The annals of University "Dunarea De Jos" of Galati fascicle VIII, ISSN 1221-4590.

[12] Xavior, M.A., Adithan, M., 2009. Determining the influence of cutting fluids on tool wear and surface roughness during turning of AISI 304 austenitic stainless steel. Journal of Materials Processing Technology 209, 900-909.

[13] Belluco, W., De Chiffre, L., 2004. Performance evaluation of vegetable-based oils in drilling austenitic stainless steel. Journal of Materials Processing Technology 148, 171-176.

[14] Julie Zhang, Rao, P.N., Mary Eckman, 2012. Experimental evaluation of a bio-based cutting fluid using multiple machining characteristics. International Journal of Modern Engineering 12 (2), 35 - 44.

[15] Rao, P.N., Julie Zhang, Marry Eckman, 2013. Experimental study and regression modeling of tool wear in CNC turning operation using soybean-based cutting fluid. Journal of Mechanical Engineering 10(1), 1-6.

[16] Rastogi, R.B., Yadav, M., 2004. Suspension of molybdenum-sulfur complexes in paraffin oil as extreme pressure lubricants. Tribology International 37, 87-92.

[17] Cambiella, A., Benito, J.M., Pazos, C., Coca, J., Hernandez, A., Fernandez, J.E., 2007. Formulation of emulsifiable cutting fluids and extreme pressure behavior. Journal of Materials Processing Technology 184, 139-145.

[18] Bierla Aleksandra., Fromentin Guillaume, Clotilde Minfray, Jean-Michel Martin, Thierry Le Mogne, Nicole Genet, 2012. Mechanical and Physico-chemical study of sulfur additives effect in milling of high strength steel. Wear 286, 116-123.

[19] Babur Ozcelik, Emel Kuran, Huseyin Cetin, M., Erhan Demirbas, 2011. Experimental investigations of vegetable based cutting fluids with extreme pressure during turning of AISI 304L. Tribology International 44, 1864-1871. 
[20] Emel Kuram, M. Huseyin Cetin, Babur Ozcelik, Erhan Demirbas 2012, Performance analysis of developed vegetable-based cutting fluids by D-optimal experimental design in turning process. International Journal of Computer Integrated Manufacturing 25 (12), 1165-1181.

[21] Emel Kuram, Babur Ozcelik, Bilgin Tolga Simsek, Erhan Demirbas, 2013. The effect of extreme pressure added vegetable based cutting fluids on cutting performance in milling. Industrial Lubrication and Tribology, 65(3) 181 193.

[22] Santos, F.D.D., Guillemet, F., 2002. New water soluble EP additive for environment friendly fluids. Industrial
Lubrication and Tribology 54, 285-290.

[23] Hussy Cetin, M., Babur Ozcelik, Emel Kuram, Erhan Demirbas, 2011. Evaluation of vegetable based cutting fluids with extreme pressure and cutting parameters in turning of AISI 304L by Taguchi method. Journal of Cleaner Production 19, 2049-2056.

[24] Clarens, A.F., Zimmerman, J.B., Landis, H.R., Hayes, K.F., Skerlos, S.J., 2004. Experimental comparison of vegetable and petroleum base oils in metalworking fluids using the tapping torque test. Proceedings of the Japan-USA Symposium on Flexible Automation, Denver; 1-6, July 19-21. 